\title{
Hodgkin Lymphoma in the West of Algeria: Panorama of Characteristics, Initial Work-up, Survival and Risk Factors Distribution
}

Tamim Alsuliman ${ }^{1}$, Amine Bekadja ${ }^{1 *}$, Abdessamed Arabi $^{1}$, Hadj Touhami ${ }^{2}$, Fatiha Mekkous-Touhami $^{2}$, Zahia Zouaoui $^{3}$, Asma Hadjeb $^{3}$, Naima Mesli $^{4}$, Nadia Houti $^{4}$, Nemra Mehalhal ${ }^{5}$, Aissa Bachiri ${ }^{6}$ and Rachid Bouhass ${ }^{1}$

${ }^{1}$ Department of Hematology and Cell Therapy, EHU-Oran University Hospital Establishment, Oran, Algeria

${ }^{2}$ Department of Hematology, CHU-Oran University Hospital Center, Oran, Algeria

${ }^{3}$ Department of Hematology, CHU-Bel Abbes, University Hospital Center, Sidi Bel Abbes, Algeria

${ }^{4}$ Department of Hematology, CHU-Tlemcen, University Hospital Center, Tlemcen, Algeria

${ }^{5}$ Department of Hematology, EPH-Mascara Public Hospital Establishment, Mascara, Algeria

${ }^{6}$ Department of Hematology, HMRUO, Algeria

"Corresponding author: Amine Bekadja, Department of Hematology and cell therapy, EHU-Oran University Hospital Establishment, Oran, Algeria, Tel: 00213773844988; Fax: 0021341421636; E-mail: mabekadja@yahoo.fr

Rec date: Feb 24, 2014, Acc date: Mar 17, 2014, Pub date: Mar 19, 2014

Copyright: (C) 2014 Bekadja A, et al. This is an open-access article distributed under the terms of the Creative Commons Attribution License, which permits unrestricted use, distribution, and reproduction in any medium, provided the original author and source are credited.

\section{Abstract}

Introduction: The principal object of this study is to represent - in maximum accuracy- the real status of Hodgkin's lymphoma in west of Algeria, we think also it serves as an adequate indicator for the epidemiological characteristics of HL patients and as an overview of these patients treatment and survival in Algeria.

Patients and methods: From December 2007 to the 1st of January 2013, 668 patients were included in this study, from the age of 15 to 88 years, and both genders. 8 hematology centers participated covering the west of Algeria. All diagnostic procedures and treatment policies were unified between the involved centers, the pilot center (Oran1) adapted a strict system for data collection, control and confirmation, WHO/REAL system was used for histological classification and ECOG system for the performance status. The therapeutic approach consisted of chemotherapy combined or not with radiotherapy according to clinical stage followed when appropriate with intensification protocol and autologous stem cell transplantation.

Results: Of our 668 patients: $53 \%$ were males, $47 \%$ females, global median age was 36 years [15-88], localized disease was presented in $22 \%$ of our study patients, while $78 \%$ presented advanced stages, rates of peripheral bulky, Mediastinal Bulky and Non-Bulky disease were: $8 \%, 45 \%$ and $47 \%$ respectively. $9 \%$ of patients had bone marrow involved by HL. $18 \%$ of patients had imaging of affected spleen, while $9 \%$ had features of affected liver. $74 \%$ of patients had one or more of B-symptoms, $68 \%$ of males and $74 \%$ of females were anemic, $28 \%$ of patients had leukocytosis $65 \%$ of all patients had nodular sclerosis subtype.

Cumulative Overall Survival was estimated in 352 evaluable patients: $59 \%$ (at 60 months), $69 \%$ (at 48 months), while $79 \%$ of patients were alive after 5 years of follow-up. Cumulative OS for males was: $64 \%$ (at 48 months), and Cumulative OS of females: $75 \%$ (48 months) P-value $>0.05$

For patients aged more or less than 45 years, Cumulative OS were 43 and 49 months respectively for the means of OS. With $\mathrm{P}=0,016$ of the 352 evaluable patients: 129 patients had reached CR and been qualified for DFS statistical analysis. Relapse rate was $16 \%$, Cumulative Disease-Free Survival was $69 \%$ (at 48 months), no statistically significant difference had been detected between patients aged more or less than 45 years $\mathrm{P}$ value $=$ 0.811 .

Conclusion: Differences in survival rates between this study and publications maybe explained partially by the very high frequency of negative prognostic factors in our cohort like bulky and advanced disease, B-symptoms, and anemia positivity rates, lack of PET-CT and radiotherapy centers number may had also affected these results, even though we found ourselves very interested in deepening further more in diagnosis, treatment and follow - up modalities standardization and development in west of Algeria in order to raise the level of health services offered to $\mathrm{HL}$ patients to meet eventually developed countries survival rates. 
Page 2 of 7

\section{Introduction}

Hodgkin's Lymphoma $(\mathrm{HL})$ is a rare malignancy, with an incidence of about 2,4 per 100.000 per year [1]. Estimated new cases and deaths from Hodgkin lymphoma in the United States in 2013 were [2]: 9290 new cases and 1180 Deaths. More than $75 \%$ of all newly diagnosed patients with adult Hodgkin lymphoma can be cured with combination chemotherapy and/or radiation therapy. American National mortality has fallen more rapidly for adult HL than for any other malignancy over the last 5 decades [3]. Clinical staging for patients with Hodgkin lymphoma includes a history, physical examination, laboratory studies (including sedimentation rate), and thoracic and abdominal/pelvic computerized tomographic (CT) scans [4].

Bone Marrow Involvement (BMI) is rare in patients with Hodgkin's lymphoma, its incidence varies between $4 \%$ and $14 \%$ in the series reported during the last thirty years [5-12], biopsy is indicated in the presence of constitutional B-symptoms or anemia, leukopenia, or thrombocytopenia. Staging laparotomy is no longer recommended. It should not be done in patients who require chemotherapy. If the laparotomy is required for treatment decisions, the risks of potential morbidity should be considered [13-16].

The staging classification that is currently used for HL was adopted in 1971 at the Ann Arbor Conference [17] with some modifications 18 years later from the Cotswold's meeting [4]. Staging has an important role in the treatment of all malignancies, but it is critically important in Hodgkin's lymphoma. Treatment of HL depends upon the stage at presentation, which is defined by anatomic location of involved sites and presence or absence of specific symptoms. Accurate staging allows optimization of therapy, improving overall survival by decreasing relapse rates. In addition, the unnecessary toxicities of extended-field radiation or overly aggressive chemotherapy may be avoided with appropriate staging. The risk of secondary malignancies, which exceeds 10 percent in several series of patients with early-stage HL [18], may also be minimized. Patient quality of life during and after therapy may be improved with tailored therapy defined by staging [19].

By identifying involved sites, staging not only defines appropriate therapy, but it also allows comparison of results of treatment among cancer centers, defines entry into clinical trials, and provides prognostic information valuable to both the physician and the patient. Beyond simple descriptions of locations of disease, these validated clinical prognostic features should be included in the evaluation of all patients with HD prior to commencing therapy [20].

Pathologists currently use the World Health Organization (WHO) modification of the Revised European-American Lymphoma (REAL) classification for the histological classification for adult Hodgkin lymphoma (HL) [18,19]. WHO/REAL classification [18-22] was adapted for this study patient's pathological classification. The principal object of this study is to represent - in maximum accuracythe real status of Hodgkin's lymphoma in west of Algeria, we think also it serves as an indicator of HL epidemiological profile and as an overview of patients treatment results in Algeria.

Although the main object of this study remain epidemiological, it also serves as a good guide for health policies planning, representing the most accurate updated national characteristics of Hodgkin lymphoma.

\section{Patients and Methods}

\section{Patients}

668 patients were included in this study, aged from 15 to 88 years, of both genders. The following hematology centers had participated, covering the west of Algeria:

Oran1: hematology department of EHUO; Oran 2: hematology department of CHUO; Oran3: hematology department of HMRUO; Tlemcen: hematology department of CHUTlm; Mascara: hematology department of EPHMas; Sidi Bel Abbes: hematology department of CHUSBA; Saida: hematology department of EPHS; Ain Temouchent: hematology department of EPHTem. By including all patients from both university and public health centers, and from hospitals of big and small cities, industrial and agricultural, by this we aimed to represent the real socio-economic status of Hodgkin's lymphoma patients in the west of Algeria.

This pre-mentioned multi-centric including system helped us also to cover most professions presented in the west Algerian community. Recruitment period for our patients was: December 2007 to January 2013.

\section{Methods}

All diagnostic procedures and treatment policies were unified between the involved centers, the pilot center (Oran1) adapted a strict system for data collection, control and confirmation, this system included: standard follow-up policy and standardized software that been installed in all centers, this software sent full and unified tables to the study data manager (Alsuliman $\mathrm{T}$ ) to be reviewed and confirmed by control committee (Bekadja MA, Bouhass R AND Alsuliman T) for the final processing. Regular meetings had been held for researchers of all centers to solve problems and to review the data managing feedback.

Initial work-up contained the following procedures: lymph node excision biopsy for histology including IHC when necessary, chest Xray, thoracic abdominal and pelvic computed tomography, bone marrow biopsy, inflammatory balance, deep and comprehensive investigation and clinical examination, complete blood count, essential systems function assessment.

Therapeutic approach consisted of chemotherapy combined or not with radiotherapy according to clinical stage followed, when appropriate, with intensification protocol and autologous stem cells transplantation. This study was planned to adhere maximally to sample homogeneity by unifying-as much as possible- all procedures, and performing consecutive meetings between researchers, clinicians and departments decision makers. We must refer here that this study had based on WHO definition of anemia $(\mathrm{Hb}<13$ gldl for men, $\mathrm{Hb}<12$ g\dl for women) [23].

\section{Results}

\section{Gender, age and residency}

Of our 668 patients: 356 were males (53\%), while 312 were females (47\%). Sex ratio was 1,14 . Median age of our patients at time of diagnosis was 36 years (15-88), and mean age was 33 years, also we divided our sample into age groups that showed with their prevalence in table 1 . 
Citation: $\quad$ Alsuliman T, Bekadja A, Arabi A, Touhami H, Mekkous-Touhami F, et al. (2014) Hodgkin Lymphoma in the West of Algeria: Panorama of Characteristics, Initial Work-up, Survival and Risk Factors Distribution. J Blood Lymph 4: 120. doi:10.4172/2165-7831.1000120

Page 3 of 7

\begin{tabular}{|l|l|l|}
\hline Age group (per years) & $\begin{array}{l}\text { Absolute } \\
\text { Number }\end{array}$ & Percentage (\%) \\
\hline 15 to 25 & 227 & $34 \%$ \\
\hline 25 to 34 & 221 & $33 \%$ \\
\hline 35 to 44 & 88 & $13 \%$ \\
\hline 45 to 54 & 55 & $8 \%$ \\
\hline 55 to 64 & 58 & $9 \%$ \\
\hline$>64$ & 19 & $3 \%$ \\
\hline Total & 668 & $100 \%$ \\
\hline
\end{tabular}

Table 1: Patients' distribution according to age groups

Every Wilaya, which can explained by the term: state, is an administrative unit may contain numerous cities, towns and villages, biggest shares were those of Oran and Tlemcen, which is justified by their bigger populations. Patients' distribution according to Wilaya of permanent residence is showed in figure 1.

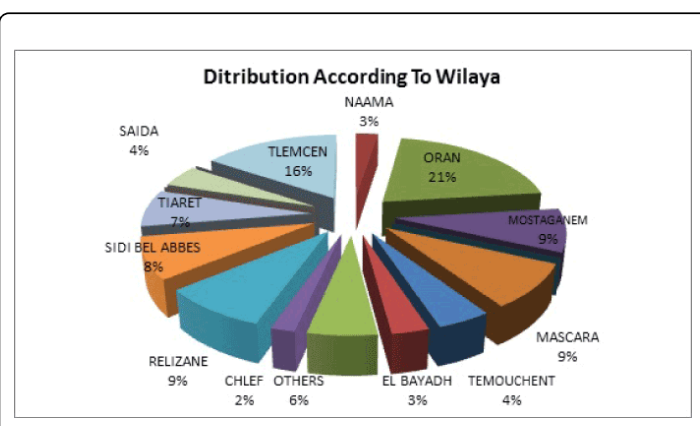

Figure 1: Patients distribution according to Wilaya of permanent residence

\section{ECOG performance status}

In order to assess our patients performance status, all involved centers had adapted ECOG system, by which our sample was staged, 523 patients $(78 \%)$ had PS $=0$ or 1 , as showed in figure 2 .

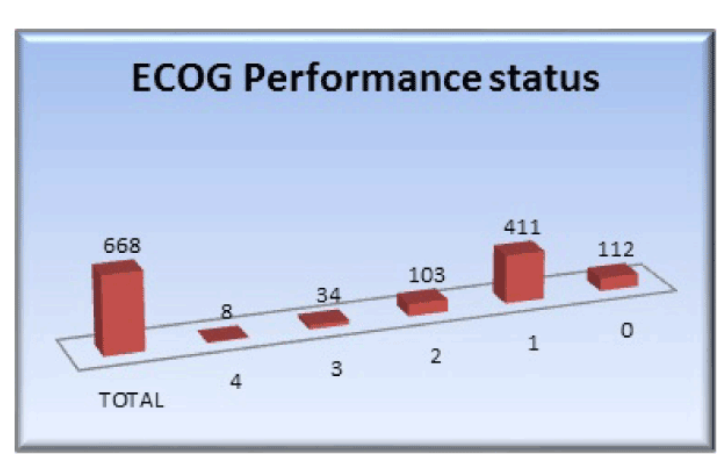

Figure 2: Distribution of patients according to ECOG system

\section{Disease-related characteristics}

Staging according to Ann-Arbor's system: For the purpose of staging we adapted Ann-Arbor's system, $10 \%$ of our patients had stage I, while $32 \%$ of them had stage II, stage III and IV were presented in $16 \%$ and $42 \%$ respectively as showed in table 2

\begin{tabular}{|l|l|l|l|l|l|}
\hline Total & IV & III & II & I & Stage \\
\hline 668 & 280 & 104 & 214 & 70 & Number \\
\hline $100 \%$ & $42 \%$ & $16 \%$ & $32 \%$ & $10 \%$ & Percentage \\
\hline
\end{tabular}

Table 2: Patients staging according to Ann-Arbor's system

It is worth noticing here that localized disease (stages I and IIA) was presented in $22 \%$ (150 patients) while all other patients (518 patients, $78 \%$ ) had advanced stages disease including stage IIB, III and IV.

Bulky disease: Due to its influence on prognosis and treatment planning, it is always recommended to estimate the accurate prevalence of bulky disease; in this study we regrouped patients into three different classes.

Peripheral bulky disease: 50 patients (8\%).

Mediastinal bulky disease: 302 patients (45\%).

Non-bulky disease: 316 patients (47\%).

The distribution of patients regarding the bulky and non-bulky disease is showed in figure 3.

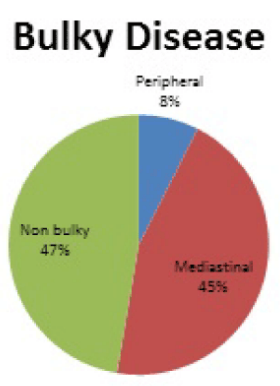

Figure 3: Distribution of bulky disease within the study patients

Localization of involved lymph nodes with reference to diaphragm: All involved lymph nodes were supra-diaphragmatic in 270 patients (40\%), while 398 patients $(60 \%)$ had infra-diaphragmatic involved lymph nodes (LNs) with or without supra-diaphragmatic LNs, 14 cases of stage I and II had infra-diaphragmatic involved lymph nodes with a rate of $4.9 \%$ of Ann-Arbor's I and II stages patients.

Involved lymphatic areas: We divided our sample into two groups according to involved lymphatic areas: the first group that includes patients who have less than four involved lymphatic areas counted 297 patients $(44 \%)$ and the second includes patients who have 4 or more involved lymphatic areas and this last group counted 371 patients (56\%).

Bone marrow involvement, spleen and liver status: Patients of this study underwent bone marrow biopsy before any lymphoma-related treatment, 605 patients (91\%) had lymphoma-free biopsy under 
Citation: $\quad$ Alsuliman T, Bekadja A, Arabi A, Touhami H, Mekkous-Touhami F, et al. (2014) Hodgkin Lymphoma in the West of Algeria: Panorama of Characteristics, Initial Work-up, Survival and Risk Factors Distribution. J Blood Lymph 4: 120. doi:10.4172/2165-7831.1000120

Page 4 of 7

microscopic examination with IHC when necessary, while 63 patients (9\%) had bone marrow involved by HL.

118 patients (18\%) had imaging features of affected spleen, either presented by spleen nodules andlor splenomegaly or by detection of involved hilar nodes, while 549 patients $(82 \%)$ had nothing of these features, one more patient had a prior splenectomy for undefined reason. 62 patients $(9 \%)$ had imaging features of affected liver, either presented by liver nodules and $/$ or hepatomegaly or by detection of involved hilar nodes, while 606 patients $(91 \%)$ had nothing of the prementioned features.

Histopathology of Hodgkin's lymphoma: All involved centers adapted the REALIWHO; in our study 436 of HL cases (65\%) were of Nodular Sclerosis (NS) subtype, while Mixed-Cellularity (MC) subtype placed second with 129 cases (19\%), finally 49 cases of HL stayed unclassified, as showed in figure 4 .

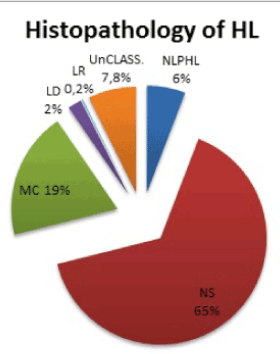

Figure 4: Histological classification

\section{B-symptoms, anemia and leukocytosis}

Of all patients 494 patients (74\%) had one or more lymphomarelated (or not otherwise explained) B-symptoms at time of diagnosis, while 174 patients $(26 \%)$ had no B-symptoms.

World Health Organization definition of anemia, $\mathrm{Hb}<13 \mathrm{~g} \backslash \mathrm{dl}$ for men, $\mathrm{Hb}<12 \mathrm{~g} \backslash \mathrm{dl}$ for women [23], was based on by all involved centers to classify our study patients, 242 males ( $68 \%$ of males) were anemic and 115 male patients (32\% of males) were not, in comparison with 230 anemic females (74\%) and 81 non-anemic females $(26 \%$ of females), these results are showed in figure 5 .

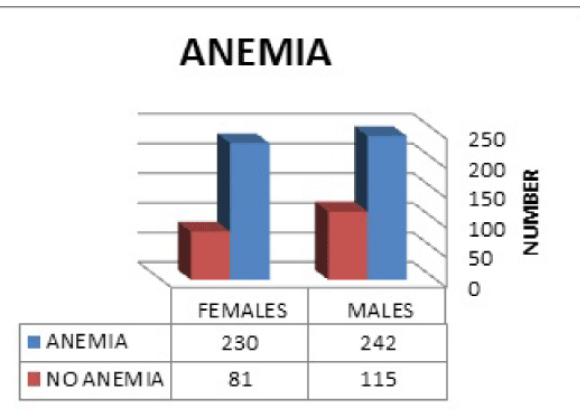

Figure 5: anemia presentation in respect to gender
Of study patients: 184 patients (28\%) had leukocytosis defined as WBC absolute count $>15000 \backslash \mu \mathrm{L}$ ), while 484 of them (72\%) had WBC count $>15000 \backslash \mu \mathrm{L}$.

\section{Survival results}

We subjected all study patients data to a second strict auditing process in order to reach the maximum exactitude in survival calculation and analysis, any inadequate, controversial and $\backslash$ or missed dates and periods in any subject's data caused this subject to experience exclusion out of survival calculation and analysis process, this procedure resulted in exclusion of 336 patients information from all groups, conserving the homogeneity and identical representation of the sample.

Cumulative Overall Survival (OS) and Disease-Free Survival (DFS) were estimated by Kaplan - Meier's method.

OS was: 59\% (at 60 months), 69\% (at 48 months), mean survival time was 49 months for the entire cohort, as showed in figure 6 .

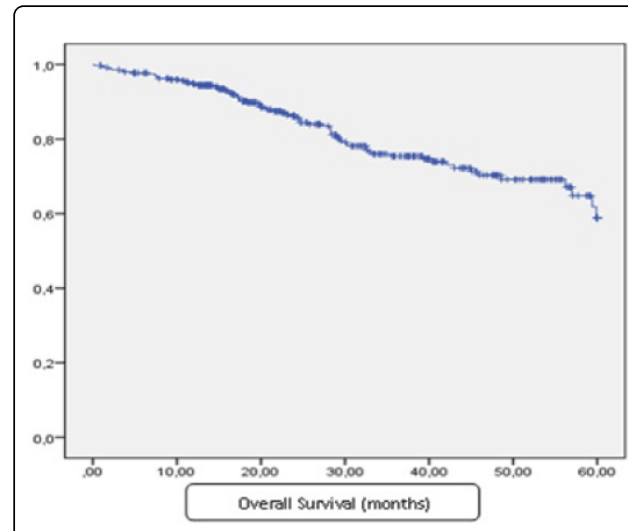

Figure 6: Cumulative overall survival

We studied also the influence of patients sex on OS, results were:

Cumulative OS-male: 64\% (at 48 months), Cumulative OS-female: $75 \%$ (48 months)

But with a P-value $>0.05$ which means that this difference of OS is not statistically significant. These results are represented in figure 7.

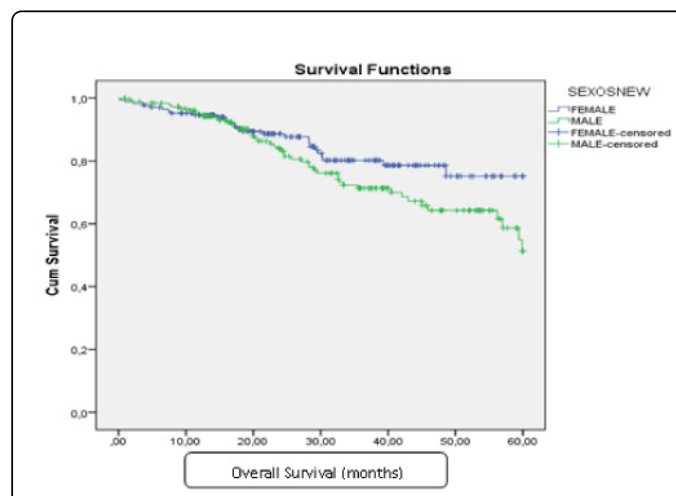

Figure 7: Cumulative overall survival by gender 
We studied also the influence of age (patients aged $\geq 45$ vs. $<45$ ) on OS, results were 43 and 49 months respectively for the means of OS. With P-value $=0.016$ and the difference is statistically significant, as showed in figure 8 .

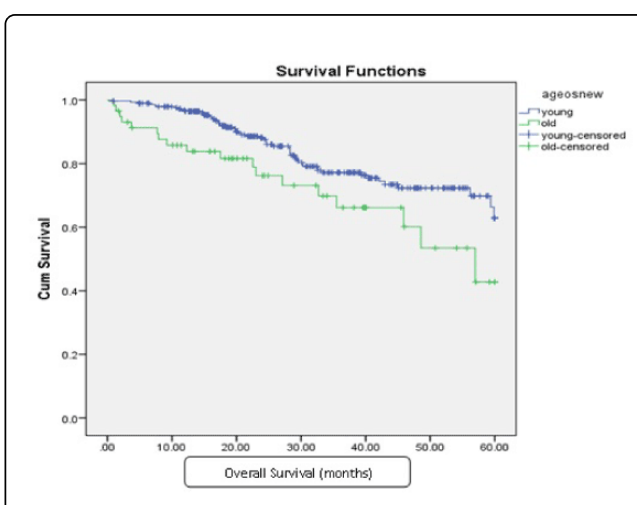

Figure 8: Cumulative overall survival by age groups

\section{Disease-Free Survival}

We defined DFS as following: the period in months between the date of post-first line Complete Remission (CR), and the date of relapse, death or study end-point.

Of our patients who passed the second auditing process: 129 patients had reached CR and been qualified for DFS statistical analysis.

$16 \%$ of patients had relapsed within the follow-up period. Cumulative Disease-Free Survival was 69\% (at 48 months), as showed in figure 9.

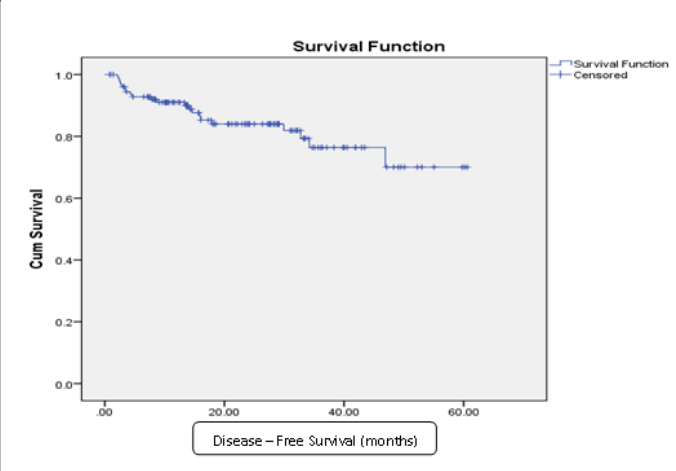

Figure 9: Cumulative disease-free survival

No statistically significant difference had been detected between patients aged more than 45 years or younger subjects, with Log Rank significance (Mantel-Cox) of 0.558.

\section{Discussion}

\section{General characteristics}

In comparison with HL historic epidemiological features in the west of Algeria between 1996 and 2005 [24], this disease incidence appears to be tripled, which may be partially explained by the better detection techniques and improved diagnostic methods in the last few years, sex ratio was almost the same, and lower than that recorded in the western publications [25], or even in those of east of Mediterranean area [26-27]. Mean and median ages appeared to be increased in comparison with the Algerian historic results (30 years) [24] probably as a result of pediatric patients non-inclusion criteria applied in this study.

According to Ann-Arbor's staging system $42 \%$ of our patients were of stages: I \& II, in comparison with the $49 \%$ recorded in Algeria from 1996 to 2005 [24], but still within the international recorded range [26-28].

Nodular sclerosis subtype was the most frequent subtype in our study (65\%), which is more than the most recent historic result in Algeria (55\%), also more than results recorded in east of Mediterranean area [26-27], but still accepted within the international range [29].

In the entire cohort, involvement rates of spleen, liver and bone marrow are pretty close to the percentages mentioned in international publications [26,27], while was within the bone marrow involvement range as mentioned world widely [30].

Regarding the performance status scaled by ECOG scoring system our results were comparable with other countries studies results which ranged between 65.4 - 84\% regarding patients who has PS 0 AND 1 $[27,31]$.

Bulky disease rate in our study is considered too high in comparison with results derived from literature [27].

$74 \%$ of our entire cohort had one or more B-symptom, which may be considered comparable in reference to other studies results that ranged between $36 \%$ to more than $90 \%[26,27,32]$.

Anemia rates were very high in both genders within our cohort, and it seems to exceed the international range recorded in Hodgkin's lymphoma patients $[26,27]$, this may be partially explained by the high frequency of anemia in Algeria (must be deeply investigated) in comparison with the international frequency rate documented by WHO which is approximately $30 \%$ [33], especially concerning both: iron deficiency, and hemolytic anemia (caused by hemoglobinopathies), also it can be related to nutritional status, and to loss of appetite caused by high rate of B-symptoms that been observed in our study, similarly effect of bone marrow involvement, advanced and bulky disease on nutrition and anemia must be investigated more profoundly within our cohort .

\section{Survival}

5 -years OS was $59 \%$, with $79 \%$ of patients alive after 5 years of follow-up, OS results were 43 and 49 months respectively With Pvalue 0,016 and the difference of OS is statistically significant between patients aged $\geq 45$ vs. $<45$ years, which reflect the importance of age as a prognostic factor in Hodgkin's disease in Algeria, while Cumulative Disease-Free Survival was 69\% (at 48 months) for the entire cohort of patients.

These results seems to be far from the international estimation of survival in HL in USA, England and other countries [27,34-40].

Differences in survival rates between this study and publications maybe explained partially by the very high frequency of negative prognostic factors in our cohort -as noticed previously- when studying bulky, advanced disease and B-symptoms positivity rates, high anemia 
rates combined with HL may also affect remarkably the survival of patients, lack of PET-CT scan follow-up (unavailable at that period in west of Algeria), also some logistic problems related to radiotherapy centers limited number may had affected this rate, even though we found ourselves very interested in deepening further more in diagnosis, treatment and follow-up modalities standardization and development in Algeria in order to raise the level of health services offered to HL patients to meet more and more the international standards of care and eventually developed countries survival rates.

\section{Closure}

In general it is important to notice that this study object is to help these group of researchers and other groups to involve more deeply in studying Hodgkin's lymphoma, either by identifying the special and unique characteristics of HL within the Algerian population, or by concluding and summarizing the last five years results of diagnosis and treatment of this disease in order to develop our methods, in cooperation-as we hope- with colleagues in other countries by their experiences and feedback to our study results.

\section{References}

1. Cartwright R, Brincker H, Carli PM, Clayden D, Coebergh JW, et al. (1999) The rise in incidence of lymphomas in Europe 1985-1992. Eur J Cancer 35: 627-633.

2. American Cancer Society. Cancer Facts and Figures 2013. Atlanta, Ga: American Cancer Society, 2013.

3. Brenner H, Gondos A, Pulte D (2008) Ongoing improvement in longterm survival of patients with Hodgkin disease at all ages and recent catch-up of older patients. Blood 111: 2977-2983.

4. Lister TA, Crowther D, Sutcliffe SB, Glatstein E, Canellos GP, et al (1989) Report of a committee convened to discuss the evaluation and staging of patients with Hodgkin's disease: Cotswolds meeting. J Clin Oncol 7: 1630-1636.

5. Munker R, Hasenclever D, Brosteanu O, Hiller E, Diehl V (1995) Bone marrow involvement in Hodgkin's disease: an analysis of 135 consecutive cases. German Hodgkin's Lymphoma Study Group. J Clin Oncol 13: 403-409.

6. Bartl R, Frisch B, Burkhardt R, Huhn D, Pappenberger R (1982) Assessment of bone marrow histology in Hodgkin's disease: correlation with clinical factors. Br J Haematol 51: 345-360.

7. Doll DC, Ringenberg QS, Anderson SP, Hewett JE, Yarbro JW (1989) Bone marrow biopsy in the initial staging of Hodgkin's disease. Med Pediatr Oncol 17: 1-5.

8. Ellis ME, Diehl LF, Granger E, Elson E (1989) Trephine needle bone marrow biopsy in the initial staging of Hodgkin disease: sensitivity and specificity of the Ann Arbor staging procedure criteria. Am J Hematol 30: 115-120.

9. Spector N, Nucci M, Oliveira De Morais JC, Maiolino A, Portugal RD, et al. (1997) Clinical factors predictive of bone marrow involvement in Hodgkin's disease. Leuk Lymphoma 26: 171-176.

10. O'Carroll D, McKenna RW, Brunning RD (1976) Bone marrow manifestations of Hodgkin's disease. Cancer 38: 1717-1728.

11. Cimino G, Anselmo AP, De Luca AM, Fidani P, Mauro F, et al. (1983) Bone marrow involvement at onset of Hodgkin's disease. Tumori 69: 47-51.

12. Howell SJ, Grey M, Chang J, Morgenstern GR, Cowan RA, et al. (2002) The value of bone marrow examination in the staging of Hodgkin's lymphoma: a review of 955 cases seen in a regional cancer centre. $\mathrm{Br} \mathrm{J}$ Haematol 119: 408-411.

13. Urba WJ, Longo DL (1992) Hodgkin's disease. N Engl J Med 326: 678-687.
14. Sombeck MD, Mendenhall NP, Kaude JV, Torres GM, Million RR (1993) Correlation of lymphangiography, computed tomography, and laparotomy in the staging of Hodgkin's disease. Int J Radiat Oncol Biol Phys 25: 425-429.

15. Mauch P, Larson D, Osteen R, Silver B, Yeap B, et al. (1990) Prognostic factors for positive surgical staging in patients with Hodgkin's disease. J Clin Oncol 8: 257-265.

16. Dietrich PY, Henry-Amar M, Cosset JM, Bodis S, Bosq J, et al. (1994) Second primary cancers in patients continuously disease-free from Hodgkin's disease: a protective role for the spleen? Blood 84: 1209-1215.

17. Carbone PP, Kaplan HS, Musshoff K, Smithers DW, Tubiana M (1971) Report of the Committee on Hodgkin's Disease Staging Classification. Cancer Res 31: 1860-1861.

18. Mauch PM, Kalish LA, Marcus KC, Coleman CN, Shulman LN, et al. (1996) Second malignancies after treatment for laparotomy staged IAIIIB Hodgkin's disease: long-term analysis of risk factors and outcome. Blood 87: 3625-3632.

19. Ng AK, Weeks JC, Mauch PM, Kuntz KM (1999) Decision analysis on alternative treatment strategies for favorable-prognosis, early-stage Hodgkin's disease. J Clin Oncol 17: 3577-3585.

20. Brice P (1998) Prognostic factors in advanced Hodgkin's disease--can they guide therapeutic decisions? N Engl J Med 339: 1547-1549.

21. Lukes RJ, Craver LF, Hall TC, et al. (1966) Report of the Nomenclature Committee. Cancer Res 26: 1311.

22. Harris NL (1999) Hodgkin's lymphomas: classification, diagnosis, and grading. Semin Hematol 36: 220-232.

23. Blanc B, Finch CA, Hallberg L, et al. (1968) Nutritional anaemias. Report of a WHO Scientific Group. WHO Tech Rep Ser 405: 1-40.

24. Abad MT, et al. (2009) Epidémiologie de la Maladie de Hodgkin en Algérie, revue Algérienne d'Hématologie 1: 8-10.

25. Hoffbrand AV, Catovsky D, Tuddenham EGD \& Green AR (2011) Postgraduate Hematology, Wiley-Blackwell, ISBN 978-4051-9180-7, Oxford.

26. Alsuliman T, AliBasha A (2013) Bone marrow involvement in Hodgkin disease, JABHS 14: 33-40.

27. Kilickap S, Barista I, Ulger S et al. (2013) Clinical Features and Prognostic Factors of Hodgkin's Lymphoma: A Single Center Experience, Balkan Med J 30: 178-185

28. Lone A and Naeem S (2011) frequency and pattern of bone marrow infiltration in Hodgkin's lymphoma. Biomedica; 27: 132-135.

29. Pileri SA1, Ascani S, Leoncini L, Sabattini E, Zinzani PL, et al. (2002) Hodgkin's lymphoma: the pathologist's viewpoint. J Clin Pathol 55: 162-176.

30. Vassilakopoulos TP1, Angelopoulou MK, Constantinou N, Karmiris T, Repoussis P, et al. (2005) Development and validation of a clinical prediction rule for bone marrow involvement in patients with Hodgkin lymphoma. Blood 105: 1875-1880.

31. Cojbašic I, Macukanovic-Golubovic L (2007) Analysis of prognostic factors in Hodgkin's lymphoma with regard to response to treatment, Medicine and Biology 14: 117-120.

32. Myers CE, Chabner BA, De Vita VT, Gralnick HR (1974) Bone marrow involvement in Hodgkin's disease: pathology and response to MOPP chemotherapy. Blood 44: 197-204.

33. Benfenatki N (2010) 6 ème Forum National de l'omnipraticien.

34. SEER (Surveillance, Epidemiology and End Results) (2013) Cancer Statistics Review, 1975-2010. National Cancer Institute.

35. Office for National Statistics (ONS) (2011) Cancer survival in England: Patients diagnosed 2005-2009 and followed up to 2010. ONS, London.

36. Coleman MP, et al. (2010) Research commissioned by Cancer Research UK, London School of Hygiene and Tropical Medicine.

37. Welsh Cancer Intelligence and Surveillance Unit (WCISU) (2010) Cancer Survival Trends in Wales 1985-2004. WCISU, Cardiff, UK.

38. Information Services Division Scotland (ISD Scotland) (2011) Cancer Statistics. Hodgkin's Disease. 
Citation: $\quad$ Alsuliman T, Bekadja A, Arabi A, Touhami H, Mekkous-Touhami F, et al. (2014) Hodgkin Lymphoma in the West of Algeria: Panorama of Characteristics, Initial Work-up, Survival and Risk Factors Distribution. J Blood Lymph 4: 120. doi:10.4172/2165-7831.1000120

Page 7 of 7

39. Northern Ireland Cancer Registry (NICR) (2011) Cancer Survival Online Statistics. Hodgkin's Lymphoma.
40. Flowers CR, Armitage JO (2010) A decade of progress in lymphoma: advances and continuing challenges. Clin Lymphoma Myeloma Leuk 10: 414-423. 